\title{
Utilization of Interdisciplinary Tumor Boards for Sarcoma Care in Germany: Results from the PROSa Study
}

Martin Eichler ${ }^{a, b}$ Dimosthenis Andreou ${ }^{c, d}$ Henriette Golcher ${ }^{e}$ Leopold Hentschel ${ }^{b}$ Stephan Richter $^{a}$ Peter Hohenberger ${ }^{f}$ Bernd Kasper ${ }^{g}$ Daniel Pink $^{d, h}$ Jens Jakob ${ }^{i}$ Hany Ashmawy ${ }^{j}$ Simone Hettmer ${ }^{k}$ Armin Tuchscherer ${ }^{l}$ Matthias Grube ${ }^{m}$ Vitali Heidt ${ }^{n}$ Christina Jentsch $^{\mathrm{b}, \mathrm{o}}$ Jessica Pablik ${ }^{\mathrm{b}, \mathrm{p}}$ Eva Wardelmann ${ }^{\mathrm{q}}$ Karl-Friedrich Kreitner ${ }^{\mathrm{r}}$ Ulrich Kneser $^{s}$ Carolin Tonus ${ }^{t}$ Pauline Wimberger ${ }^{b, u, v}$ Olaf Schoffer ${ }^{b, w}$ Peter Reichardt ${ }^{x}$ Markus Wartenberg ${ }^{y}$ Maria Eberlein-Gonska ${ }^{z}$ Martin Bornhäusera, ${ }^{a}$ Jochen Schmitt ${ }^{b, w}$ Markus K. Schuler ${ }^{\mathrm{a}}$

${ }^{a}$ Clinic and Polyclinic for Internal Medicine I, University Hospital Carl Gustav Carus, Dresden, Germany; ${ }^{b}$ National Center for Tumor Diseases (NCT/UCC), Dresden, Germany; ' ${ }^{C}$ epartment of General Orthopedics and Tumor Orthopedics, University Hospital Münster, Münster, Germany; ${ }^{d}$ Sarcoma Center Berlin-Brandenburg, Helios Hospital, Bad Saarow, Germany; ${ }^{\mathrm{e} C l i n i c}$ for Surgery, University Hospital Erlangen, Erlangen, Germany; ${ }^{\text {Division }}$ of Surgical Oncology and Thoracic Surgery, Mannheim University Medical Center, University of Heidelberg, Mannheim, Germany; ${ }^{9}$ Interdisciplinary Tumor Center, Sarcoma Unit, Mannheim University Medical Center,

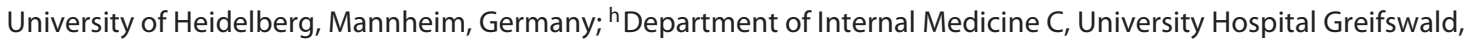
Greifswald, Germany; ${ }^{i}$ Clinic for General, Visceral, and Pediatric Surgery, University Hospital Goettingen, Goettingen, Germany; ${ }^{j}$ Clinic for General, Visceral, and Pediatric Surgery, University Hospital Dusseldorf, Dusseldorf, Germany; ${ }^{k}$ Center of Pediatrics and Adolescent Medicine, University Hospital Freiburg, Freiburg, Germany; 'University of Cologne, Department I of Internal Medicine, Center for Integrated Oncology Aachen Bonn Cologne Duesseldorf, Cologne, Germany; ${ }^{\mathrm{m} C l i n i c}$ and Polyclinic for Internal Medicine III, University Hospital Regensburg, Regensburg, Germany; ${ }^{n}$ The Scientific Institute of Office-Based Hematologists and Oncologists, Cologne, Germany; ${ }^{\circ}$ Department of Radiotherapy and Radiation Oncology, Faculty of Medicine and University Hospital Carl Gustav Carus, Technical

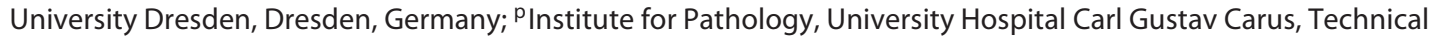
University Dresden, Dresden, Germany; ${ }^{9}$ Gerhard Domagk Institute for Pathology, University Hospital Münster, Münster, Germany; ${ }^{r}$ Clinic and Polyclinic for Diagnostic and Interventional Radiology, University Hospital Mainz, Mainz, Germany; ${ }^{5}$ Department of Hand, Plastic, Reconstructive and Microsurgery, BG Trauma Center Ludwigshafen and Heidelberg University, Ludwigshafen, Germany; ${ }^{\mathrm{t} C l i n i c}$ for General and Visceral Surgery, Asklepios Hospital

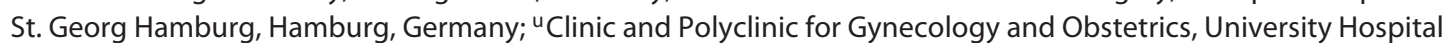
Carl Gustav Carus, Technical University Dresden, Dresden, Germany; ${ }^{\vee}$ German Cancer Consortium (DKTK), Partner

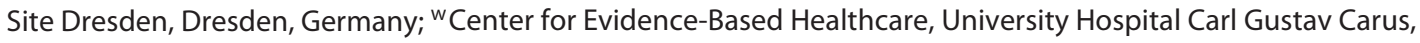
Technical University Dresden, Dresden, Germany; ${ }^{\times}$Sarcoma Center Berlin-Brandenburg, Helios Hospital Berlin Buch, Berlin, Germany; ${ }^{y}$ German Sarcoma Foundation, Wölfersheim, Germany; ${ }^{z}$ Department of Quality and Medical Risk Management, University Hospital Carl Gustav Carus, Technical University Dresden, Dresden, Germany

\section{Keywords}

Sarcoma care $\cdot$ Sarcoma treatment and diagnosis · Tumor board utilization · Observational study · Orphan disease

\begin{abstract}
Background: Data on institutional structures of sarcoma care in Germany are scarce. The utilization of an interdisciplinary tumor board (IDTB) is an essential part of modern cancer care. We investigated to which extent and when IDTB
\end{abstract}

\section{karger@karger.com} www.karger.com/ort

Karger ${ }^{\prime \prime}=$ BOPEN ACCESS (c) 2021 The Author(s)

Published by S. Karger AG, Basel

This is an Open Access article licensed under the Creative Common Attribution-NonCommercial-4.0 International License (CC BY-NC) (http://www.karger.com/Services/OpenAccessLicense), applicable to the online version of the article only. Usage and distribution for commercial purposes requires written permission.
Correspondence to:

Martin Eichler, martin.eichler@ uniklinikum-dresden.de 
are used in sarcoma care. We hypothesized that IDTB before treatment initiation were used more often at certified cancer centers and at high-volume centers and that IDTB utilization increased over time. Methods: From 2017 to 2020 we conducted a prospective cohort study, undertaking major efforts to include the whole spectrum of sarcoma treatment facilities. To analyze potential predictors of IDTB utilization, we calculated multivariable logistic regressions. Results: Patients and survivors ( $n=1,309)$ from 39 study centers (22 tertiary referral hospitals, 9 other hospitals, and 8 officebased practices) participated; $88.3 \%$ of the patients were discussed at some stage of their disease in an IDTB $(56.1 \%$ before treatment, $78 \%$ after therapy, and $85.9 \%$ in metastatic disease). Hypotheses were confirmed regarding the utilization of IDTB in certified cancer centers (vs. all others: OR = $5.39 ; 95 \% \mathrm{Cl} 3.28-8.85)$ and the time of diagnosis (2018/2019 vs. until 2013: $\mathrm{OR}=4.95 ; 95 \% \mathrm{Cl} 2.67-9.21)$. Conclusion: Our study adds to the evidence regarding the institutional structures of sarcoma care in Germany. Utilization of a tumor board before therapy seems to be in an implementation process that is making progress but is far from complete. Certification is a possible tool to accelerate this development.

(c) 2021 The Author(s)

Published by S. Karger AG, Basel

\section{Introduction}

In recent years, the centralization of sarcoma treatment at dedicated sarcoma centers has been advocated by many authors and international guidelines $[1,2]$. The process of centralization has developed differently around the world [2-4], and in Germany a certification program was implemented recently in 2018 [5]. Before then, the title "sarcoma center" was not linked to any administrative requirements.

In recent years, several studies - especially from the French Network NetSarc - have been published, providing evidence that sarcoma treatment at certified centers is beneficial $[6,7]$. In Germany, such studies do not exist so far, and large observational multicenter studies of sarcoma patients are rare. It is difficult to convince study centers to participate and recruit patients for such studies, especially in low-volume facilities. As a result, the data available regarding patients treated in such facilities is particularly unsatisfactory.

The possibility of using centralized resources to collect data of any kind on a broader scale in sarcoma patients is - inter alia for historical reasons - more limited in Germany than in other countries. However, in recent years more and more centralized structures (clinical cancer registries [8], central collection of health insurance data [9], and initiatives to establish a general sarcoma register [10]) have evolved, but to date no sufficient database exists in Germany. This is one of the reasons why we con- ducted the PROSa study, of which initial results beyond this paper have already been published [11-13].

We identified utilization of an interdisciplinary tumor board (IDTB), especially utilization of a specialized sarcoma board, as one of the criteria for adequate treatment of sarcoma patients. There is evidence that utilization of an IDTB improves relapse-free survival in sarcoma patients, and several systematic reviews have reported a variety of positive effects on cancer patients in general [14, 15]. We were interested in potentially predictive factors for utilization of an IDTB regarding structural as well as treatment-related factors.

With this paper we want to address the following question: to which extent and when were IDTB used to support treatment decisions? We hypothesized that an IDTB prior to treatment initiation was used more often at certified cancer centers, at high-volume centers, and in patients treated initially at our recruiting centers, and that the use of IDTB increased over the years.

\section{Methods}

\section{Recruitment, Participation, and Data Sources}

We conducted a Germany-wide prospective cohort study (www.uniklinikum-dresden.de/prosastudie). In 2017 we contacted sarcoma treatment hospitals and office-based practices via a variety of channels (medical societies and research networks) and tools (email lists, personal letters, and advertisements) for participation in our study network. The study aimed to gather information on a variety of patient-reported outcomes, clinical data on the patient level, and structural data of participating study centers. Baseline data of sarcoma patients were collected between September 2017 and February 2019, while follow-up data for each patient were collected 6 and 12 months after recruitment. Incident and prevalent adult patients and survivors of all sarcoma subtypes were included (the detailed list of the included entities can be found in the paper by Eichler et al. [12]). We excluded patients who were mentally or linguistically unable to fill out the study questionnaires.

Eligible patients were asked to participate in the study centers during visits and sometimes by phone or letter.

Patient-reported outcomes and sociodemographic data were submitted by the participants to the study coordination center at the University Hospital Dresden by mail or online. Clinical information of study participants and structural data of participating study centers was submitted online by the participating centers to the study coordination center using case report forms. Data collection was performed using REDCap (Vanderbilt University, Nashville, TN, USA) electronic data capture tools hosted at the Technical University Dresden [16].

\section{Statistical Analysis}

Discrete variables were reported in absolute and relative frequencies, and non-normally distributed continuous variables (Shapiro-Wilk test) were presented as medians (interquartile range; IQR). We used a flow chart to display the study participation (online suppl. Fig. 1; for all online suppl. material, see www. karger.com/doi/10.1159/000516262). Participation of medical facilities as well as of patients was cartographically represented on a map of Germany (online suppl. Fig. 2). Descriptive structural variables of the recruiting study centers were characterized by the 
Table 1. Characteristics of the recruiting centers and numbers of recruited patients

\begin{tabular}{|c|c|c|c|c|c|}
\hline \multirow[t]{2}{*}{ Variable } & \multirow[t]{2}{*}{ Value } & \multicolumn{2}{|c|}{$\begin{array}{l}\text { Recruiting } \\
\text { facilities }(n=39)\end{array}$} & \multicolumn{2}{|c|}{ Patients } \\
\hline & & $n$ & $\%$ & $n$ & $\%$ \\
\hline \multirow[t]{3}{*}{ Recruiting facility - type } & Office-based practice & 8 & 21 & 51 & 4 \\
\hline & Primary and secondary hospitals & 9 & 23 & 266 & 20 \\
\hline & Tertiary referral hospital & 22 & 56 & 992 & 76 \\
\hline \multirow[t]{6}{*}{ Recruiting facility - certifications (multiple answers) } & Organ cancer center $(\mathrm{C})$ & 2 & 5 & 206 & 16 \\
\hline & Oncological center (CC) & 22 & 56 & 437 & 33 \\
\hline & Oncological center of excellence (CCC) & 12 & 31 & 716 & 55 \\
\hline & No certification & 5 & 13 & 41 & 3 \\
\hline & Sarcoma center (self-declared) & 15 & 38 & 1,039 & 79 \\
\hline & Certified sarcoma center or application process & 21 & 54 & 1,195 & 91 \\
\hline \multirow[t]{5}{*}{ Recruiting center - patients in 2018} & $1-25$ & 16 & 41 & 108 & 4 \\
\hline & $26-100$ & 8 & 21 & 165 & 17 \\
\hline & $101-500$ & 8 & 21 & 567 & 43 \\
\hline & $>500$ & 5 & 13 & 462 & 35 \\
\hline & Missing & 2 & 5 & 7 & 1 \\
\hline \multirow[t]{3}{*}{ Initial treatment in the recruiting center $(n=667)$} & Office-based practice & I & I & 3 & 0 \\
\hline & Primary and secondary hospitals & I & I & 96 & 14 \\
\hline & Tertiary referral hospital & I & I & 595 & 85 \\
\hline \multirow[t]{4}{*}{ Initial treatment somewhere else $(n=571)$} & Office-based practice & I & I & 40 & 7 \\
\hline & Other hospitals & I & I & 329 & 58 \\
\hline & University hospital/specialized center & I & I & 130 & 23 \\
\hline & Unknown place & / & l & 72 & 13 \\
\hline In-house IDTB $(n=667)$ & Yes & 34 & 87 & 666 & 99.9 \\
\hline In-house sarcoma board $(n=667)$ & Yes & 17 & 44 & 562 & 84 \\
\hline External IDTB $(n=667)$ & Yes & 5 & 13 & 1 & 0.1 \\
\hline
\end{tabular}

Data was self-provided by the participating centers. /, data not available for this analysis.

number and number of recruiting patients. Baseline data of the participants were compared to available data of nonparticipants (age, sex, and time since diagnosis) and published German cancer registry data for sarcomas in general with data from $2013(n=$ 6,846 ) [17] and for soft tissue sarcoma (STS) with data from 20022013 ( $n=33,308)$ [18] (online suppl. Fig. 3).

IDTB utilization was graphically displayed for general use, use before therapy, user after therapy, and use after metastasis. IDTB utilization before therapy was graphically displayed stratified by year of diagnosis (i.e., until 2013, 2014-2015, 2016-2017, and 2018-2019), place of initial treatment (in-house tertiary referral hospitals, in-house all others, external university hospital/specialized center, and external all others), and number of patients treated in 2018 in the study centers (i.e., $\leq 25,26-100,101-500$, and $\geq 500$ )

As structural information concerning the treating medical facilities was available only for those patients who were treated consistently at 1 center, we performed 2 multivariable logistic regressions (analysis 1 and analysis 2) to evaluate potentially associated factors of pretherapy IDTB use. We used analysis 1 for hypothesis testing and analysis 2 for explorative analysis. In analysis 1 we included those patients who were treated exclusively at one of the study centers (in-house patients) and excluded additionally those without treatment and outcome data. In analysis 2 we included all patients (in-house and external) with treatment and outcome data. Model variables for logistic regression were chosen based on theoretical, empirical, and statistical considerations. We included age, gender (male or female), sarcoma type (STS, bone sarcoma [BS], or gastrointestinal stromal tumor [GIST]), year of diagnosis (till 2013, 2014-2015, 2016-2017, or 2018-2019), tumor localization (trunk, limbs, or elsewhere), malignancy (yes or no), grading (low, high, or not applicable/unknown), T stage (T1, T2 to T4, or other/ unknown), and M stage (no, yes, or suspicion/unknown) on a patient level in both analyses. For analysis 1 we also included the number of patients treated at each study center in $2018(\leq 25,26-$ $100,101-500$, or $\geq 500$ ) and certification (CCC or all others) on a facility level. For analysis 2 we included the initial treatment place (in-house tertiary referral hospitals, in-house all others, external university hospital/specialized center, and external all others) on a facility level.

Model variables were included in regression after being tested for multicollinearity (correlation $<0.8$ ). Logistic regression was performed using backward selection procedures for variables on a patient level, with $p>0.1$ as an exclusion criterion. Variables on the facility level were tested for an interaction effect. 95\% CI were calculated. $p<0.05$ was considered statistically significant. Variables on a facility level were kept in the model and tested for potential interaction effects. Statistical analysis was performed using IBM SPSS Statistics version 25.0 (Armonk, NY, USA).

\section{Results}

\section{Description of the Study Centers}

Forty-four study centers, some with a huge network of collaborating practices, agreed to take part, and 39 recruited patients (online suppl. Fig. 2). Twenty-two were 
Table 2. Baseline description

\begin{tabular}{|c|c|c|}
\hline Variable & Value & $\begin{array}{l}\text { All }(n=1,309) \\
n(\%) \text { or median (IQR) }\end{array}$ \\
\hline \multirow[t]{2}{*}{ Sex } & Female & $624(47.7)$ \\
\hline & Male & $681(52.2)$ \\
\hline Age at diagnosis & & $54.1(41.8-64.2)$ \\
\hline Time since diagnosis & & $2.3(0.7-5.9)$ \\
\hline \multirow[t]{3}{*}{ Sarcoma type } & STS & $910(69.7)$ \\
\hline & BS & $236(18.1)$ \\
\hline & GIST & $159(12.2)$ \\
\hline \multirow[t]{3}{*}{ Site } & Trunk & $629(48.2)$ \\
\hline & Limbs & $610(46.7)$ \\
\hline & Somewhere else & $66(5.1)$ \\
\hline \multirow[t]{3}{*}{ Grading } & Low grade & $158(12.1)$ \\
\hline & High grade & $705(53.9)$ \\
\hline & Not accessible/unknown/not graded & $446(34.1)$ \\
\hline \multirow[t]{2}{*}{ Malignancy of the tumor } & Locally aggressive and rarely metastatic & $108(8.3)$ \\
\hline & Malignant & $1,197(91.7)$ \\
\hline \multirow[t]{3}{*}{ Metastasis at diagnosis } & No & $928(71.4)$ \\
\hline & Yes & $133(10.2)$ \\
\hline & Unknown & $238(18.3)$ \\
\hline \multirow[t]{4}{*}{ Tumor recurrence } & No recurrence & $947(72.6)$ \\
\hline & Recurrence & $324(24.8)$ \\
\hline & Suspicion & $13(1.0)$ \\
\hline & Unknown & $21(1.6)$ \\
\hline \multirow[t]{3}{*}{ Treatment intention } & Curative & $964(73.9)$ \\
\hline & Palliative & $311(23.8)$ \\
\hline & Unknown & $29(2.2)$ \\
\hline \multirow[t]{4}{*}{ Disease status } & Complete remission & $579(44.4)$ \\
\hline & Partial remission/stable disease & $379(29.0)$ \\
\hline & Progress & $194(14.9)$ \\
\hline & Unknown & $153(11.7)$ \\
\hline \multirow[t]{3}{*}{ Treatment status } & In treatment & $418(32.1)$ \\
\hline & Not in treatment & $878(67.3)$ \\
\hline & Unknown & $8(0.6)$ \\
\hline \multirow[t]{3}{*}{ Surgery } & No & $158(12.1)$ \\
\hline & Yes & $1,137(87.2)$ \\
\hline & Unknown & $10(0.8)$ \\
\hline \multirow[t]{3}{*}{ Chemotherapy } & No & $686(52.6)$ \\
\hline & Yes & $602(46.2)$ \\
\hline & Unknown & $16(1.2)$ \\
\hline \multirow[t]{3}{*}{ Radiotherapy } & No & $775(59.4)$ \\
\hline & Yes & $498(38.2)$ \\
\hline & Unknown & $32(2.5)$ \\
\hline \multirow[t]{3}{*}{ Tyrosine kinase inhibitor } & No & $1,055(80.8)$ \\
\hline & Yes & $202(15.5)$ \\
\hline & Unknown & $48(3.7)$ \\
\hline
\end{tabular}

tertiary referral hospitals (56\%), 9 (23\%) were other hospitals, and $8(21 \%)$ were office-based practices. Five study centers had no certification, 22 were oncological centers (CC), and 12 were oncological centers of excellence (CCC) (Table 1).

\section{Recruitment and Participation}

Patients were contacted between September 2017 and January 2019. Not all of the study centers were able to document patients not willing to participate. Therefore, we had to extrapolate contacted patients from the data of centers where such data was available. With 1,644 known contacted patients, we estimate that around 1,900 patients were contacted overall. A total of 1,309 patients participated in the study. The estimated participation rate was $69 \%$ (online suppl. Fig. 1).

Seventy-six percent of the patients were recruited in tertiary referral hospitals, $20 \%$ in other hospitals, and $4 \%$ in office-based practices. Thirty-five percent were recruited from facilities that treated more than 500 sarcoma 
Table 3. Use of an IDTB before therapy: stratified analysis

\begin{tabular}{|c|c|c|c|c|}
\hline Variable & Value & $\begin{array}{l}\text { IDTB utilization, } \\
n(\%)\end{array}$ & $\begin{array}{l}\text { No IDTB utilization, } \\
n(\%)\end{array}$ & Unknown \\
\hline $\begin{array}{l}\text { Year of diagnosis } \\
(n=1,271)\end{array}$ & $\begin{array}{l}\text { Until } 2013 \\
2014-2015 \\
2016-2017 \\
2018-2019\end{array}$ & $\begin{array}{r}104(43.3) \\
86(49.1) \\
215(61.8) \\
151(66.2)\end{array}$ & $\begin{array}{r}136(46.7) \\
89(50.9) \\
133(38.2) \\
77(33.8)\end{array}$ & $\begin{array}{r}155 \\
36 \\
65 \\
24\end{array}$ \\
\hline $\begin{array}{l}\text { Place of first treatment } \\
(n=1,238)\end{array}$ & $\begin{array}{l}\text { In house - hospital/practice } \\
\text { In house - maximum care } \\
\text { External - practice } \\
\text { External - hospital } \\
\text { External - university hospital/specialized center } \\
\text { External - unknown place }\end{array}$ & $\begin{array}{r}58(65.2) \\
391(72.8) \\
7(19.4) \\
55(25.8) \\
34(44.7) \\
5(18.5)\end{array}$ & $\begin{array}{r}31(34.8) \\
146(27.2) \\
29(80.6) \\
158(74.2) \\
42(55.3) \\
22(81.5)\end{array}$ & $\begin{array}{r}10 \\
31 \\
4 \\
116 \\
54 \\
45\end{array}$ \\
\hline $\begin{array}{l}\text { Patients treated in } 2018 \\
(n=662)^{\mathrm{a}}\end{array}$ & $\begin{array}{l}\text { Up to } 25 \\
11-100 \\
101-500 \\
\text { More than } 500\end{array}$ & $\begin{array}{r}24(61.5) \\
70(88.6) \\
192(72.2) \\
159(67.1)\end{array}$ & $\begin{array}{r}15(28.5) \\
9(13.4) \\
74(27.8) \\
78(32.9)\end{array}$ & $\begin{array}{r}6 \\
6 \\
13 \\
16\end{array}$ \\
\hline $\begin{array}{l}\text { Comprehensive cancer } \\
\text { center }(n=667)^{\mathrm{a}}\end{array}$ & $\begin{array}{l}\text { No } \\
\text { Yes }\end{array}$ & $\begin{array}{l}108(50.5) \\
341(82.8)\end{array}$ & $\begin{array}{l}106(49.5) \\
71(17.2)\end{array}$ & $\begin{array}{l}13 \\
28\end{array}$ \\
\hline
\end{tabular}

a Data are available only for patients initially treated in participating centers.

patients in 2018, and another $43 \%$ were recruited in facilities treating between 100 and 500 patients.

Fifty-four percent of the recruited patients received their initial treatment at one of our study centers ( $14 \%$ at other hospitals and $85 \%$ at tertiary referral hospitals), $46 \%$ were initially treated at nonparticipating sites ( $7 \%$ at office-based practices, $58 \%$ at other hospitals, $23 \%$ t university hospitals/specialized centers, and $13 \%$ at unknown sites; Table 1).

Based on data from Ressing et al. [17], who reported 6,846 new cases in Germany in 2012, we could recruit in 2019 with 277 incident patients $4.0 \%$ of all incident sarcoma cases in Germany.

\section{Description of the Study Population}

Six hundred twenty-four (47.7\%) of the participants were female. Nine hundred ten $(69.7 \%)$ were diagnosed with STS, 236 (18.1\%) with BS, and 159 (12.2\%) with GIST. The median age at diagnosis was 54.1 years (IQR 41.8-64.2). The median time from diagnosis was 2.3 years (IQR 0.7-5.9); 48.2\% of the patients had sarcomas of the trunk, and $47.7 \%$ had sarcomas of the extremities. More than half of the patients were diagnosed with a high-grade sarcoma (53.9\%); $91.7 \%$ of the tumors were malignant; $7.8 \%$ were locally aggressive or rarely metastasizing, and $10.2 \%$ of the patients had primary metastases. At study entry, $73.9 \%$ were treated with a curative intent, and $23.8 \%$ were treated with a palliative intent (Table 2 ; online suppl. Table 1).

\section{Nonparticipant Analysis and Comparison to Cancer} Registry Data

Women declined slightly more often to participate than men $(49.3 \%$ of nonparticipants and $47.7 \%$ of participants). Comparing means, nonparticipants were 2.2 years younger than participants, and the time since diagnosis was 0.4 years longer for nonparticipants (online suppl. Fig. 3).

Slightly fewer women participated in PROSa as was to be expected from cancer registry data (47.3 vs. $50.0 \%$ ). PROSa participants were, on average, much younger than registered sarcoma patients (54.1 vs. 67.5 years overall). The largest difference was observed in BS (36.2 vs. 52.0 years). The participation of patients with STS was similar to cancer registry data; fewer GIST patients participated (12.2 vs. $22 \%)$ and more BS patients (18.1 vs. $9 \%)$ took part (online suppl. Fig. 3).

\section{Tumor Board Utilization}

All study centers had access to an IDTB. Seventeen (44\%) had a specialized sarcoma board established in 2019 (Table 1). Moreover, 88.3\% of patient cases were discussed at some stage of their disease in an IDTB; $56.1 \%$ of the cases were discussed before treatment initiation, $78 \%$ were discussed after therapy, and $85.9 \%$ were discussed after the development of metastatic disease (online suppl. Fig. 4).

Stratified analysis showed that pretherapy IDTB utilization increased over the years from $43.3 \%$ before 2013 to $66.2 \%$ in $2018 / 2019$. Patients treated in recruiting centers (in-house patients) had much higher rates of pretherapy 
Table 4. Results of the multivariable logistic regressions

\begin{tabular}{|c|c|c|c|c|c|c|c|}
\hline \multirow[t]{2}{*}{ Variable } & \multirow[t]{2}{*}{ Value } & \multicolumn{3}{|c|}{$\begin{array}{l}\text { Analysis 1: IDTB use before therapy } \\
\text { in in-house patients }(n=621)\end{array}$} & \multicolumn{3}{|c|}{$\begin{array}{l}\text { Analysis 2: IDTB use before therapy } \\
\text { in all patients }(n=978)\end{array}$} \\
\hline & & OR & $95 \% \mathrm{CI}$ & $p$ & OR & $95 \% \mathrm{CI}$ & $p$ \\
\hline \multirow{4}{*}{$\begin{array}{l}\text { Place of initial } \\
\text { treatment }\end{array}$} & In-house tertiary referral hospital (reference) & I & 1 & 1 & _- & - & _- \\
\hline & In-house all others & l & l & / & 0.73 & $0.44-1.22$ & 0.23 \\
\hline & External all others & / & l & / & 0.12 & $0.09-0.18$ & $<0.01$ \\
\hline & External university hospital/specialized center & l & I & I & 0.31 & $0.19-0.52$ & $<0.01$ \\
\hline Certification (CCC) & No CCC vs. CCC & 5.34 & $3.25-8.77$ & $<0.01$ & l & l & l \\
\hline \multirow[t]{4}{*}{ Year of diagnosis } & Till 2013 (reference) & - & - & - & - & - & - \\
\hline & $2014-2015$ & 2.24 & $1.21-4.16$ & 0.01 & 1.13 & $0.72-1.79$ & 0.60 \\
\hline & $2016-2017$ & 3.56 & $2.10-6.04$ & $<0.01$ & 1.93 & $1.31-2.85$ & $<0.01$ \\
\hline & $2018-2019$ & 5.11 & $2.76-9.49$ & $<0.01$ & 2.83 & $1.82-4.40$ & $<0.01$ \\
\hline \multirow[t]{4}{*}{ Patients in 2018} & $\leq 25$ (reference) & - & - & - & I & I & I \\
\hline & $26-100$ & 2.05 & $0.71-5.86$ & 0.18 & 1 & 1 & I \\
\hline & $101-500$ & 0.66 & $0.30-1.47$ & 0.31 & l & l & l \\
\hline & $\geq 500$ & 0.81 & $0.37-1.77$ & 0.81 & l & l & l \\
\hline \multirow[t]{3}{*}{ Location } & Trunk (reference) & - & - & - & - & - & - \\
\hline & Limbs & 1.69 & $1.06-2.71$ & 0.03 & 1.53 & $1.08-2.16$ & 0.02 \\
\hline & Somewhere else & 0.66 & $0.29-1.48$ & 0.31 & 0.92 & $0.47-1.80$ & 0.81 \\
\hline \multirow[t]{3}{*}{ Grading } & Low grade (reference) & - & - & - & - & - & - \\
\hline & High grade & 1.90 & $1.06-3.41$ & 0.03 & 1.85 & $1.17-2.90$ & 0.01 \\
\hline & Not applicable/unknown & 1.51 & $0.80-2.83$ & 0.20 & 1.60 & $0.94-2.72$ & 0.08 \\
\hline \multirow[t]{3}{*}{ Sarcoma type } & STS (reference) & Excluded $^{\mathrm{a}}$ & Excluded $^{\mathrm{a}}$ & Excluded ${ }^{\mathrm{a}}$ & - & - & - \\
\hline & BS & Excluded $^{\mathrm{a}}$ & Excluded $^{\mathrm{a}}$ & Excluded $^{\mathrm{a}}$ & 2.28 & $1.43-3.63$ & $<0.01$ \\
\hline & GIST & Excluded $^{\mathrm{a}}$ & Excluded $^{a}$ & Excluded $^{a}$ & 0.60 & $0.34-1.05$ & 0.07 \\
\hline
\end{tabular}

Variables before selection: analysis 1: age, gender, sarcoma type, year of diagnosis, place of tumor, malignancy, grading, T stage, $\mathrm{M}$ stage, number of patients treated in 2018, and certification; analysis 2: age, gender, sarcoma type, year of diagnosis, place of tumor, malignancy, grading, $\mathrm{T}$ stage, $\mathrm{M}$ stage, initial treatment place, and facility type. /, variable was not available for this analysis; - , reference category. ${ }^{\text {a }}$ For statistical reasons (backward selection, $p>0.1$ ).

IDTB use than patients initially treated somewhere else (external patients). When only comparing in-house patients, high-volume facilities did not use IDTB more often than facilities with lower volumes. Patients treated at CCC had a much higher chance (83\%) of being discussed in an IDTB than those from centers without this kind of certification (51\%) (Table 3).

Univariate analysis was confirmed by both multivariable regression models.

The confirmatory multivariable regression analysis 1 with in-house patients only showed that patients treated at CCC had more than 5 times higher odds of being discussed in an IDTB than those from centers without such a certification $(\mathrm{OR}=5.39$; 95\% CI 3.28-8.85; $p<0.01)$. Patients treated in 2018/2019 had nearly 5 times higher odds of being discussed in an IDTB than patients diagnosed until 2013 (OR $=4.95 ; 95 \%$ CI 2.67-9.21; $p<0.01$ ). No increased odds were found in facilities treating many sarcoma patients. Patients with tumors of the extremities had 1.69 (95\% CI 1.06-2.71; $p=0.03$ ) higher odds of getting an IDTB than those with a tumor of the trunk. Patients with high-grade tumors also had higher odds of being discussed than low-grade patients ( $\mathrm{OR}=1.90 ; 95 \%$ CI 1.06-3.41; $p=0.03$; Table 4 ). We found no interaction effects.

In exploratory multivariable regression analysis 2 , which included all of the patients, external patients had much lower odds of being discussed in IDTB before therapy than in-house patients. Patients with tumors of the extremities had 1.53 (95\% CI 1.08-2.16; $p=0.02$ ) higher odds of being discussed in an IDTB than those with a tumor of the trunk. Patients with high-grade tumors had higher odds of being discussed than low-grade patients (i.e., 1.85 ; 95\% CI 1.17-2.90; $p=0.01$ ). BS patients had increased odds of being discussed than STS patients (OR $=2.28 ; 95 \%$ CI $1.43-3.63 ; p<0.01$; Table 4 ). We found no interaction effects.

\section{Discussion}

\section{Tumor Board Utilization}

There is evidence that utilization of a specialized IDTB improves relapse-free survival in sarcoma patients [14]. 
A study in patients with Ewing sarcoma showed increased overall survival when using a specialized reference board [19]. We were not able to measure the use of specialized sarcoma boards in German sarcoma patients directly and only measured that of IDTB in general. A recent umbrella review on the impact of IDTB in all cancer types discussed a broad range of aspects of potential impact. The review reported improvements in the diagnostic process, in patients' quality of life, and in treatment processes and strategies, as well as in several other aspects like patient care coordination, reduced waiting times, and patient satisfaction. Impact on survival was nonhomogeneous [15].

We are not aware of studies on the prevalence of IDTB use in sarcoma care. Overall IDTB utilization was nearly $90 \%$ in our population, whereas IDTB utilization before therapy, with little more than $50 \%$, was comparatively low. Our hypotheses were thus partially confirmed. The increase in IDTB utilization over time was substantial, indicating institutional changes in medical facilities in recent years. Differences between in-house and external patients were substantial too, especially when comparing in-house patients from tertiary referral hospitals with external patients from primary and secondary hospitals or office-based practices. A CCC certification is the highest available standard of cancer care in Germany. Ninety-five percent of patients should be discussed in IDTB before therapy. This is reflected in the observed differences between study centers with and without such a certification. No differences were found between in-house patients from high- or low-volume centers. This might be since we could not distinguish between IDTB in general and specialized sarcoma boards.

It remains to be seen whether the newly implemented certification program for sarcoma centers in Germany [5] will lead to an increase in IDTB use. In order to achieve the certification, centers must not only conform with a series of structural requirements but also meet several predetermined benchmarks, such as discussing at least $95 \%$ of sarcoma patients in IDTB prior to treatment and after local therapy, as well as discussing all patients with metastatic disease. Between the implantation of the certification program in 2018 and March 2021, twelve centers had been certified as sarcoma centers [20].

\section{Strengths and Limitations}

Through the PROSa study, we were able to establish a broad network of recruiting study centers all over Germany. We included the complete spectrum of medical facilities, even highly specialized ones such as special clinics for plastic reconstructions. Furthermore, we were able to include a high number of patients for an observational study of a rare disease. Participation was, with an estimated $69 \%$, comparatively high, indicating a high patient motivation. Despite that success, we cannot claim that our study centers represent a cross-section of sarcoma treatment facilities in Germany. Most of our study participants were recruited at high-volume centers and tertiary referral hospitals. We assume that this does not represent the average situation of sarcoma care in Germany and therefore expect the existence of a selection bias on the level of medical facilities. At the peak in 2019, we were able to recruit $4 \%$ of the incident patients of 1 year. We would argue that, under the given institutional circumstances and administrative obstacles, an observational study is not able to reach out sufficiently to low-volume facilities. In consequence, small and well-differentiated tumors are probably underrepresented in our study. However, nearly half of the study participants were not initially treated at the recruiting study centers. Those patients were much more often treated at office-based practices and primary or secondary hospitals. They might not represent all patients from those facilities (patients who are successfully treated would probably not be referred to another center) but they are an important fraction as they encompass those who had to change their treatment facility for medical reasons.

The observed differences between nonparticipants and participants in terms of sex, age, and time since diagnosis were minor. We do not expect strong biases here. Concerning the sex ratio of our cohort, we observed only minor differences compared to participants with published cancer registry data. A huge difference, however, was observed in age. Study participants were much younger than patients from the cancer registry analyses. As there is no large age difference between participants and nonparticipants (the latter are even younger), one reason might be that older patients are more often treated in low-volume facilities, which are underrepresented in our study. It might also be the case that older patients were not properly recruited at the study centers. A third reason is probably that we had a survivor selection in those patients who were recruited during follow-up, as older patients die at higher rates compared to younger patients. Regarding sarcoma types, GIST patients are under- and BS patients are overrepresented in comparison with cancer registry data, which might reflect the distribution of patients at individual study centers with different disease focuses.

Our descriptive data show the high diversity of the disease and that we were able to recruit patients from all sarcoma subgroups (except for skin sarcomas), tumor sites, and disease stages. The received treatments differed widely as was to be expected. As we included incident patients as well as prevalent patient, survivors' time since diagnosis differed widely. Since a considerable, though not exactly quantifiable, proportion of patients (particularly those with STS) receive follow-up care at clinics for only some (sometimes 5) years, it is to be assumed that participants who are $>5$ years after diagnosis and had a relapse or were still on medication are overrepresented, as 
they would still visit a participating study center. As we could only include living patients in our study, all data collected retrospectively must be interpreted with caution due to a survivor bias.

\section{Conclusion}

In the absence of centralized data collection structures in Germany so far, our large observational multicenter study of sarcoma patients adds to the evidence regarding the institutional structures of sarcoma care in Germany. Utilization of a tumor board before therapy seems to be in an implementation process that is making progress but is far from complete. Certification appears to be a tool to accelerate this development.

\section{Acknowledgement}

Without the support of the following individuals, the conduction of our study would not have been possible. We are very grateful for the support received.

Christiane Noack, Gina Lehmann, Christine Peikert, Luise Mütze, Armina Kalirad, Dr. Alexander Kohler, Prof. Gustavo B. Baretton, Prof. Mechthild Krause, Beate Hornemann, Prof. Ralf-Thorsten Hoffmann, Dr. Chiara Valentini, Dr. Fabian Lohaus, Prof. Gerhard Ehninger, Dr. Hagen Fritsche, Dr. Martin Rössler, Dr. Thomas Datzmann, Dr. Freya Trautmann, Susan Vogl, Diana Löscher, Prof. Michael Laniado, Prof. Jürgen Weitz, Dr. Johanna Kirchberg, Christine Griebsch, PD Dr. med. Christine Hofbauer, Prof. Klaus-Dieter Schaser (University Hospital Dresden), Dr. Lothar Müller, Dr. Carsten Janssen, Johanna Jansen, Kim-Aline Kraft (office-based practice for oncology UnterEms), Dr. Gerdt Hübner, Renate Günther (office-based practice ohO Ostholstein), Prof. Dr. Torsten Kluba, Kerstin Spranger, Nicole Thoms-Ruckau, Juliane Gehre (Dresden-Friedrichstadt Hospital), Dr. Stefan Fuxius, Dr. Andreas Karcher, Tanja Löschner (office-based practice for oncology Heidelberg), Claudia Fendrich, Monika Mathew, Dr. Franka Menge (University Hospital Mannheim), Prof. Ralph Naumann, Katja Schneider (St. Marien Hospital Siegen), Prof. Ulrich Kaiser, Monika Morban (St. Bernward Hospital Hildesheim), Martina Popp (Helios Hospital Emil von Behring Berlin), Simone Micheel (Helios Hospital Bad Saarow), Dr. Michael Ehrsam (office-based practice for oncology Schwarzwald Alb), Prof. Robert Grützmann, Katrin Hindel, Dr. Nikolaos Vassos, Dr. Maximilian Brunner, Dr. Justus Baecker, Dr. Katja Fechner, Dr. Thomas Förtsch, Dr. Claudia Handtrack, Dr. Felix Wiesmüller, Dr. Veronika Zver, Stefania Puta, Dr. Sabine Semrau, Prof. Rainer Fietkau, Prof. Matthias Beckmann, Judith Bürner, Lena Kellner, Dr. Dorotha Lubgan (University Hospital Erlangen), Dr. Annette Reichhardt, Dr. Per-Ulf Tunn (Helios Hospital Berlin-Buch), Prof. Stephan Mose, Dr. Mohammed Reda Al-Omar (Hospital Schwarzwald-Baar), Gaby Horstmann, Dr. Tanja Trarbach (Wilhelmshaven Hospital), Prof. Thomas Wölfel, Prof. Susanne Singer, Manuel Baltzereit, Sergio Armando Zapata Bonilla, Dr. Marius Fried (University Hospital Mainz), Dr. Annegret Kunitz, Anne Leopold (Vivantes Hospital Berlin), Prof. Wolfram Knoefel, Dr. med. Stephen Fung (University Hospital Düsseldorf), Prof. Christian A. Schmidt, Jeanette Bahr (University Hospital Greifswald), Dr. Johannes Mohm, Dr. Gabriele Prange-Krex, Catrin Krüger (office-based practice Dres. Mohm, Prange-Krex,
Dresden), Dr. Susanne Pfitzner-Dempfle, Marion Sollgan (officebased practice for hematology and oncology Kaiserslautern), Stephanie Erdmann, Dorothea Zaech, Dr. Karl Verpoort (officebased practice Dres. Verpoort and Wierecky, Hamburg), Dr. Ursula Vehling-Kaiser, Dr. Ana Hoffmann, Maxi Hofmann (officebased practice H.O.T. Landshut), Prof. Gerlinde Egerer, Martina Gronkowski (University Hospital Heidelberg), Prof. Hans-Günter Derigs, Diana Isabella Dmytrow, Claudia Bund (Hospital Frankfurt Höchst), Dr. Amir Bigdeli, Steffen Nolte (BG Hospital Ludwigshafen), Prof. Claus-Henning Köhne, Ute Schubert (University Hospital Oldenburg), Christiane Reinert, Dr. Anke SchlenskaLange, Dr. Nadia Maguire (Barmherzige Brüder Regensburg Hospital), Dr. Regine Mayer-Steinacker, Evelyn Mack, Dr. Verena I. Gaidzik (University Hospital Ulm), Prof. Roland Ulrich, Christina Thielen, Lars Pester, Cäcilia Kaul (University Hospital Köln), Dr. Carsten Schlickewei, Dr. Matthias Primel (University Hospital Hamburg Eppendorf), Roswitha Rausch, Dr. Thomas Hawighorst (Fulda Hospital), Claudia Bosch, Prof. Christoph Anthuber (Starnberg Hospital), Barbara Wirth, Prof. Holger Bannasch (University Hospital Freiburg), Dr. Nicola Gökbuget, Lena Schütz, Dr. Marit Ahrens (University Hospital Frankfurt), Tanja Hofmann, Prof. Christian Stroszczynski (University Hospital Regensburg), Nadine Sykosch (Asklepios Hospital St. Georg Hamburg), Inga Kreisel (University Hospital Göttingen), Prof. Dr. Jalid Sehouli (Charité Berlin), Prof. Uta Dirksen (University Hospital Essen), and Karin Arndt (German Sarcoma Foundation).

\section{Statement of Ethics}

This study was approved by the ethics committee of the Technical University of Dresden (AZ: EK 1790422017) and the ethics committees of the participating centers, and it was conducted in accordance with the Declaration of Helsinki. The study participants gave written informed consent. This study is registered under NCT03521531 on ClinicalTrials.gov.

\section{Conflict of Interest Statement}

J.S. received consulting fees from Novartis, Sanofi, A.L.K., and Lilly, all outside of this work. J.J. received fees from Lilly and Boehringer Ingelheim, all outside of this work. L.H. received fees from Servier, outside of this work. D.A. received lecture fees from Lilly and Implantcast, all outside of this work. D.P. received fees for consulting services from Lilly, PharmaMar, and Roche and fees for lectures from Lilly and PharmaMar, all outside of this work. M.K.S. received research funding from PharmaMar and Novartis, all outside of this work. P.R. reports fees from Bayer, Clinigen, BMS, Roche, MSD, Deciphera, Novartis, Pfizer, PharmaMar, Lilly, and Amgen, outside of the submitted work. P.W. received research funding from Amgen, AstraZeneca, MSD, Novartis, Pfizer, PharmaMar, Roche, Clovis, and Tesaro and honoraria/expenses and fees for consulting/advisory board service from the companies mentioned above as well as from TEVA and Eisai, all outside of this work. O.S. received consulting fees from Novartis outside of this work. M.W., S.H., H.A., J.P., C.J., M.G., M.E., B.K., M.B., V.H., K.-F.K., M.E.-G., U.K., A.T., H.G., E.W., C.T. and S.R. declare that no conflict of interests exists.

\section{Funding Sources}

The PROSa study was funded by the German Cancer Aid (grant No. 111713). 


\section{Author Contributions}

M.E. wrote this article and analyzed the data. M.E., M.K.S. and L.H. developed the questionnaires and study design. J.S. and M.K.S. developed the conception of this study and supervised, with M.B., the work throughout the whole study. E.W. and J.P. supervised the development of the inclusion criteria. C.J., K.-F.K., P.W., P.R., M.W., and M.E.-G., supervised this study as part of the sci- entific advisory board. M.E., D.A., H.G., M.K.S., J.S., L.H., S.R., P.H., B.K., O.S., and J.J. developed the statistical analysis plan for this paper. D.A., H.G., S.R., P.H., B.K., D.A., D.P., J.J., H.A., S.H., A.T., M.G., V.H., U.K., C.T., P.W., P.R., and M.K.S. were responsible for the recruitment of patients or recruited patients directly. All of the authors revised this paper critically and approved the version for publication.

\section{References}

1 Andritsch E, Beishon M, Bielack S, Bonvalot S, Casali P, Crul M, et al. ECCO essential requirements for quality cancer care: soft tissue sarcoma in adults and bone sarcoma - A critical review. Crit Rev Oncol Hematol. 2017 Feb;110:94-105.

2 Casali PG, Abecassis N, Aro HT, Bauer S, Biagini $\mathrm{R}$, Bielack $\mathrm{S}$, et al.; ESMO Guidelines Committee and EURACAN. Soft tissue and visceral sarcomas: ESMO-EURACAN clinical practice guidelines for diagnosis, treatment and follow-up. Ann Oncol. 2018 Oct;29 suppl 4:iv51-67.

3 Dangoor A, Seddon B, Gerrand C, Grimer R, Whelan J, Judson I. UK guidelines for the management of soft tissue sarcomas. Clin Sarcoma Res. 2016 Nov;6(1):20.

4 von Mehren M, Randall RL, Benjamin RS, Boles S, Bui MM, Conrad EU 3rd, et al. Soft Tissue Sarcoma, Version 2.2016, NCCN Clinical Practice Guidelines in Oncology. J Natl Compr Canc Netw. 2016 Jun;14(6):758-86.

5 Deutsche Krebsgesellschaft. Protokoll zur Sitzung der Zertifizierungskommission Modul Sarkomzentren, 25.02.2019. Available from: https://www.krebsgesellschaft.de/zertkommprotokolle.html?file=files/dkg/deutsche-krebsgesellschaft/content/pdf/Zertifizierung/Protokolle_Zertkomm/SAR_Protokoll_190225. pdf\&cid=61328 [cited 2021 Jan 11].

6 Derbel O, Heudel PE, Cropet C, Meeus P, Vaz G, Biron P, et al. Survival impact of centralization and clinical guidelines for soft tissue sarcoma: A prospective and exhaustive population-based cohort. PLoS One. 2017 Feb; 12(2):e0158406.
7 Canter RJ, Smith CA, Martinez SR, Goodnight JE Jr, Bold RJ, Wisner DH. Extremity soft tissue tumor surgery by surgical specialty: a comparison of case volume among oncology and non-oncology-designated surgeons. J Surg Oncol. 2013 Sep;108(3):142-7.

8 Bundesanzeiger. Bundeskrebsregisterdatengesetz. Bundesgesetzblatt. 2009 Aug;1(53): 2707-8.

9 Bundesanzeiger. Digitale-Versorgung-Gesetz. Bundesgesetzblatt. 2019 Dec;1(49):2562-84

10 Institut für Klinische Krebsforschung IKF GmbH. GISAR. Available from: https://sarkom.expert/gisar/ [cited 2021 Jan 11].

11 Schoffer O, Roessler M, Datzmann T, Andreou D, Jakob J, Eichler M, et al. Medical care and survival of soft-tissue and bone sarcoma patients: Results and methodological aspects of a German subnational cohort study based on administrative healthcare data. Oncol Res Treat. 2020;(Dec):1-8.

12 Eichler M, Hentschel L, Richter S, Hohenberger P, Kasper B, Andreou D, et al.; The PROSa Study Group. The Health-Related Quality of Life of Sarcoma Patients and Survivors in Germany-Cross-Sectional Results of a Nationwide Observational Study (PROSa). Cancers (Basel). 2020 Nov;12(12):3590.

13 Eichler M, Richter S, Hohenberger P, Kasper B, Andreou D, Heidt V, et al. Current State of Sarcoma Care in Germany: Results of an Online Survey of Physicians. Oncol Res Treat. 2019;42(11):589-98.
14 Blay JY, Soibinet P, Penel N, Bompas E, Duffaud F, Stoeckle E, et al. Improved survival using specialized multidisciplinary board in sarcoma patients. Ann Oncol. 2017 Nov;28(11): 2852-9.

15 Specchia ML, Frisicale EM, Carini E, Di Pilla A, Cappa D, Barbara A, et al. The impact of tumor board on cancer care: evidence from an umbrella review. BMC Health Serv Res. 2020 Jan;20(1):73.

16 Harris PA, Taylor R, Thielke R, Payne J, Gonzalez N, Conde JG. Research electronic data capture (REDCap) - a metadata-driven methodology and workflow process for providing translational research informatics support. J Biomed Inform. 2009 Apr;42(2):377-81.

17 Ressing M, Wardelmann E, Hohenberger P, Jakob J, Kasper B, Emrich K, et al. Strengthening health data on a rare and heterogeneous disease: sarcoma incidence and histological subtypes in Germany. BMC Public Health. 2018 Feb;18(1):235.

18 Saltus CW, Calingaert B, Candrilli S, Lorenzo M, D’yachkova Y, Otto T, et al. Epidemiology of adult soft-tissue sarcomas in Germany. Sarcoma. 2018 Apr;2018:5671926.

19 Kreyer J, Ranft A, Timmermann B, Juergens $\mathrm{H}$, Jung $\mathrm{S}$, Wiebe $\mathrm{K}$, et al. Impact of the Interdisciplinary Tumor Board of the Cooperative Ewing Sarcoma Study Group on local therapy and overall survival of Ewing sarcoma patients after induction therapy. Pediatr Blood Cancer. 2018 Dec;65(12):e27384.

20 Deutsche Krebsgesellschaft. Oncomap. Available from: https://oncomap.de/centers? selectedOrgan=Sarkome [cited 2021 Mar 16]. 